\title{
Investigation of the Pechmann reaction between 2,7-dihydroxynaphthalene and ethyl acetoacetate with different condensing agents. Synthesis of benzocoumarin and benzochromone systems and their bi- and bis-derivatives
}

\author{
Hakan Kolancılar* and Ülkü Oyman \\ Department of Chemistry, Faculty of Arts and Sciences, University of Trakya, 22030 Edirne, Turkey \\ E-mail : alara_tr@yahoo.com_Fax:090-0284-2137053
}

Manuscript received 19 July 2002, revised 25 February 2003, accepted 2 April 2003

\begin{abstract}
Attempts were made to synthesise the benzocoumarin and benzochromone systems by Pechmann reaction. As an extension, it was also planned to make bi- and bis-derivatives of these compounds. 2,7-Dihydroxynaphthalene (DHN) and ethyl acetoacetate (EAA) were chosen as starting materials and $80 \% \mathrm{H}_{2} \mathrm{SO}_{4}$, PPA and $\mathrm{HClO}_{4}$ were used as condensing agents. $\mathrm{H}_{2} \mathrm{SO}_{4}$ gave a benzochromone with a low yield together with isomeric benzocoumarins. PPA gave angular benzocoumarin and benzochromone but no linear benzocoumarin was obtained. When $\mathrm{HClO}_{4}$ was employed the isomeric benzocoumarins were obtained with no indication of the formation of benzochromone ring.

Attempts were also made to couple some of the compounds synthesised. Only one bi-benzocoumarin was obtained in one case. No angular benzocoumarin and angular benzochromone compounds gave the coupling reaction. Also, to obtain bisderivatives, the Mannich reaction was applied.
\end{abstract}

Benzocoumarins and benzochromones have been investigated and synthesised since 1800's because of their pharmacological properties ${ }^{1}$ and other uses ${ }^{2}$. There are many synthetic methods to obtain these compounds including Pechmann $^{3 a}$, Perkin $^{3 b}$, Knoevenagel ${ }^{3 c}$ and Reformatsky reactions $s^{3 d}$.

In this study Pechmann-Duisberg reaction which is an important reaction for the development of coumarin chemistry was employed to synthesise benzocoumarins. The Pechmann reaction is based on the condensation of a substituted phenol with a $\beta$-keto ester in acidic conditions. Three factors that effect the product distribution of the reaction are : (i) the structure of the $\beta$-keto ester, (ii) the structure of phenol and (iii) condensing agents. Different condensing agents have been used for these reactions, e.g. $\mathrm{H}_{2} \mathrm{SO}_{4}{ }^{3 \mathrm{a}}$, $\mathrm{HCl}^{4}, \mathrm{P}_{2} \mathrm{O}_{5}{ }^{5}, \mathrm{POCl}_{3}{ }^{6}, \mathrm{ZnCl}_{2}{ }^{7}$. The reaction is named as Simonis reaction when $\mathrm{P}_{2} \mathrm{O}_{5}$ is used as the condensing agent. Recently, new methods have been developed instead of the classical ones by taking environmental conditions into consideration, using ionic liquids ${ }^{8}$, clays ${ }^{9}$ and microwave irradiation ${ }^{10}$. The main product obtained from the Pechmann reaction is always coumarin when $\mathrm{H}_{2} \mathrm{SO}_{4}$ is used except two reactions giving coumarin and chromone together ${ }^{11}$.

Two different isomeric benzocoumarins were obtained from the condensation reaction of 2,7-dihydroxynaphthalene (1) and ethyl acetoacetate (EAA) with $\mathrm{H}_{2} \mathrm{SO}_{4}{ }^{12,13}$. It was also shown that benzocoumarin and benzochromone were formed together when $\mathrm{PPE}^{14}$ was used as condensing agent instead of $\mathrm{H}_{2} \mathrm{SO}_{4}$. The products obtained from the Pechmann reaction by using different condensing agents are listed in Table 1.

Table 1. The compounds obtained from Pechmann and Simonis reactions according to condensing agent

$\begin{array}{lll}\begin{array}{ll}\text { Condensing } \\ \text { agent }\end{array} & \begin{array}{l}\text { The obtained } \\ \text { compds. }\end{array} & \begin{array}{l}\text { M.p. } \\ \left({ }^{\circ} \mathrm{C}\right)\end{array} \\ \text { Dry HCl }^{a} & \text { Ang. Benzocoumarin } & 277 \\ \mathrm{Con} \mathrm{H}_{2} \mathrm{SO}_{4}{ }^{c} & \text { Ang. Benzocoumarin } & 276 \\ \mathrm{H}_{2} \mathrm{SO}_{4}(80 \%)^{b} & \text { Ang. Benzocoumarin } & 321 \\ & \text { Lin. Benzocoumarin } & 267 \\ \mathrm{H}_{2} \mathrm{SO}_{4}(80 \%)^{d} & \text { Lin. Benzocoumarin } & - \\ \mathrm{None}^{b} & \text { Ang. Benzocoumarin } & - \\ \mathrm{PPE}^{e} & \text { Ang. Benzocoumarin } & 276 \\ & \text { Lin. Benzocoumarin } & 219 \\ & \text { Ang. Benzocoumarin } & 235\end{array}$

${ }^{a}$ Ref. 15. ${ }^{b}$ Ref. $12 .{ }^{c}$ Ref. $16 .{ }^{d}$ Ref. 13. ${ }^{e}$ Ref. 14.

The products from the Pechmann reactions were obtained by using different condensing agents viz. $\mathrm{H}_{2} \mathrm{SO}_{4}(80 \%)$, $\mathrm{HClO}_{4}$, PPA (Scheme 1).

Benzocoumarins $(2,3)$ and a benzochromone (4) were obtained together when $80 \% \mathrm{H}_{2} \mathrm{SO}_{4}$ was used. As mentioned before, conc. $\mathrm{H}_{2} \mathrm{SO}_{4}$ gives only coumarin except in two cases reported in literature ${ }^{11}$. Benzochromone was formed with a low yield when $80 \% \mathrm{H}_{2} \mathrm{SO}_{4}$ was used. Since 


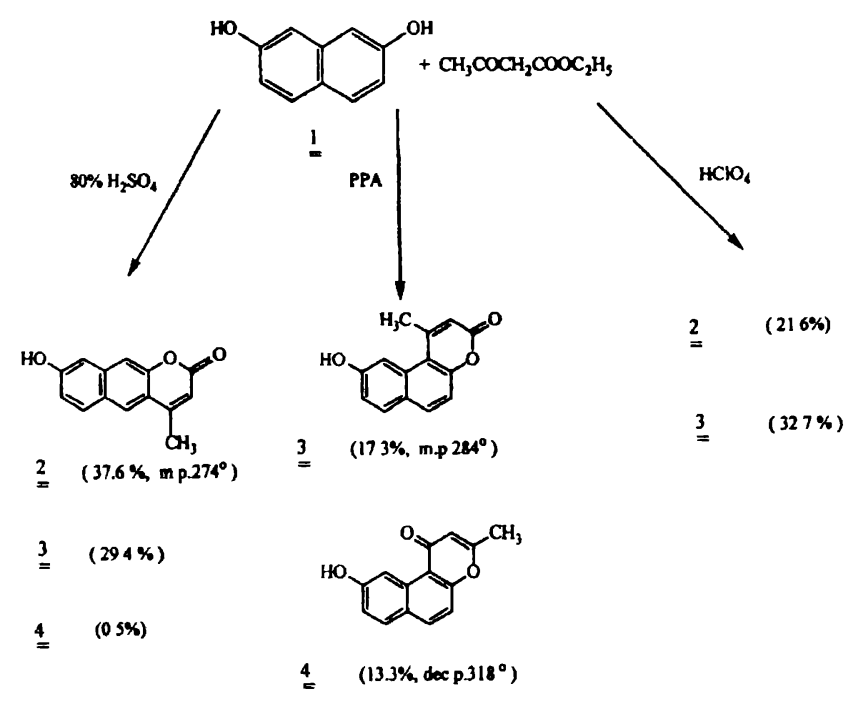

Scheme 1

all three reactions gave chromones with $\mathrm{H}_{2} \mathrm{SO}_{4}$, a new mechanistic approach is needed to explain the difference from the reported mechanism ${ }^{17}$. Chromone ring was also formed with PPA but $\mathrm{HClO}_{4}$ gave only isomeric benzocoumarins and no benzochromones.

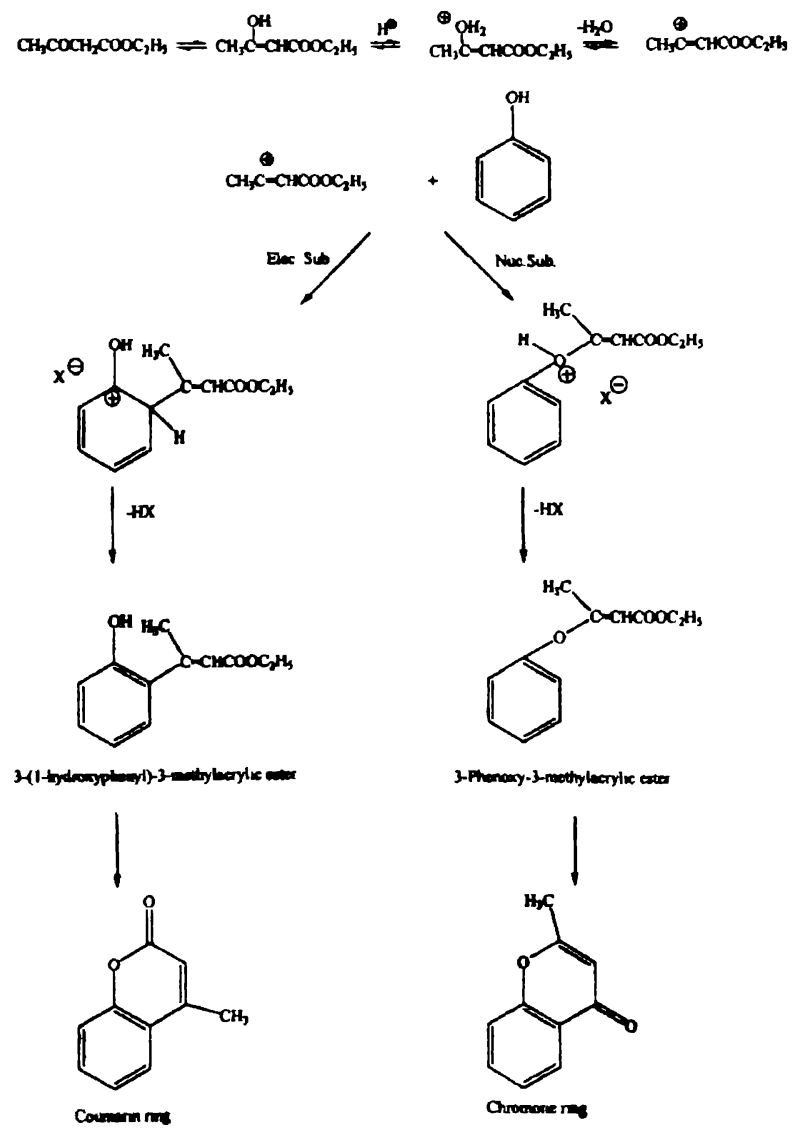

Scheme 2
According to mechanism we proposed, the first step of the Pechmann reaction is the formation of a vinylic carbocation, as accepted by all given mechanisms, in acidic conditions of EAA (Scheme 2). The second step is attachment of vinylic carbocation to ortho-position of phenol to form the coumarin ring, that is, the route of reaction is an electrophilic aromatic substitution to form 3-(1-hydroxyphenyl)-3-methylacrylic ester as intermediate.

In the presence of phosphoric acid derivatives the reaction between phenol and $\beta$-keto ester gives chromone and the reaction is known as Simonis reaction. It is reported that both the Pechmann and Simonis reactions proceed through an onium salt occurred by attack of phenolic oxygen as nucleophile to the vinylic carbocation. In this route, $\beta$-phenoxyacrylic ester is formed as intermediate which led to the formation of a chromone. The reaction route can be accepted as a $\mathrm{S}_{\mathrm{N}} 1$ reaction in this case. We observed that in all the Pechmann reactions, the yields of coumarins are better than those of chromones.

The second part of the study involves synthesis of biand bis-derivatives of benzocoumarins and benzochromones. From isomeric benzocoumarins only linear benzocoumarin gave bi-structure. From angular benzocoumarin and also angular benzochromone bi- and bis-derivatives could not be obtained because of steric hindrance.

To obtain bi-benzocoumarin from linear benzocoumarin, we first tried oxidative coupling ${ }^{18}$, but only starting material was recovered. In the second attempt to synthesise
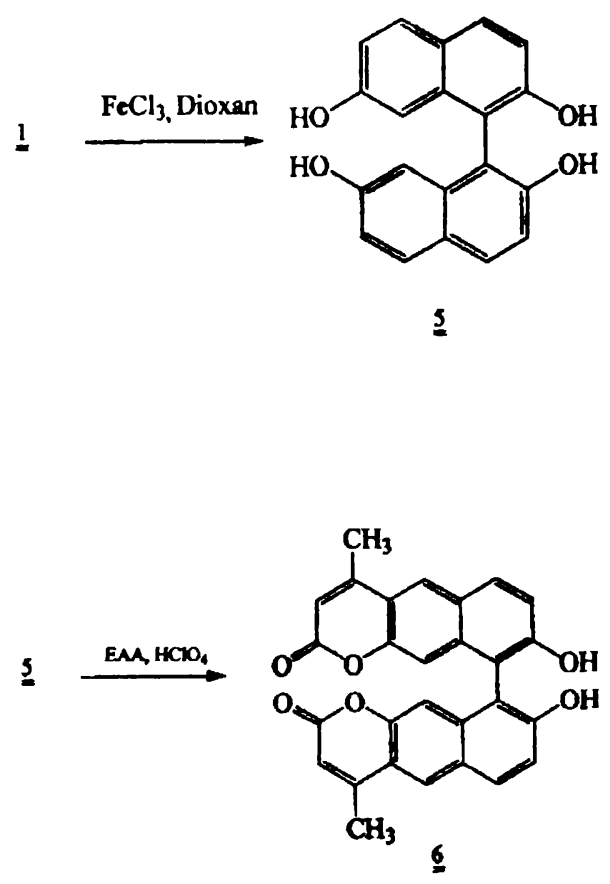

Scheme 3 
bibenzocoumarin with oxidative coupling, the reaction was applied to 2,7-dihydroxynaphthalene to obtain $2,2^{\prime}, 7,7^{\prime}$ tetrahydroxy[1,1'-binaphthyl]. It was then converted to the bibenzocoumarin structure using Pechmann reaction (Scheme 3).

Mannich reaction ${ }^{19}$ was applied to obtain bisbenzocoumarin compounds. In this case bis-structure was formed instead of Mannich base which is the regular product of this reaction (Scheme 4).

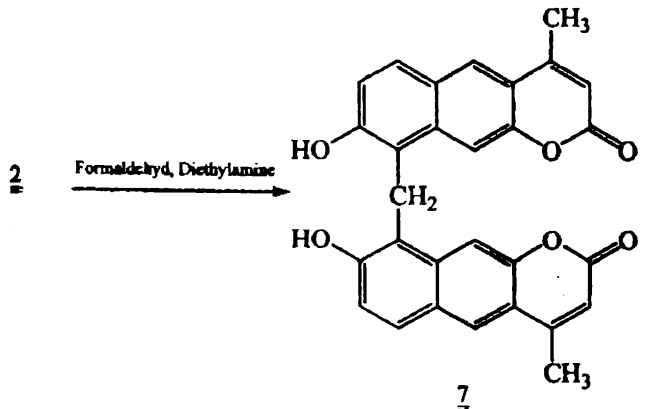

Scheme 4

\section{Results and discussion}

The Pechmann reaction was tried to obtain benzocoumarin and benzochromone systems by using different condensing agents. For this purpose, condensation reaction of 2,7-dihydroxynaphthalene and EAA were carried out with $80 \% \mathrm{H}_{2} \mathrm{SO}_{4}, \mathrm{HClO}_{4}$ and PPA respectively.

The results obtained from these condensing agent were found to be parallel to the results reported earlier. It is shown that chromone ring is formed in a poor yield when dilute $\mathrm{H}_{2} \mathrm{SO}_{4}$ is used. Using PPA as condensing agent a better yield of benzochromone was obtained. Linear benzochromone couldn't be obtained with PPA in our study, probably because other researchers used other phosphoric acid derivatives as condensing agent ${ }^{18}$. $\mathrm{HClO}_{4}$ was used for the first time in this study as a condensing agent giving both the isomeric benzocoumarins similar to ones obtained with $\mathrm{H}_{2} \mathrm{SO}_{4}$.

The results indicate that the stability of intermediates eases the formation of the benzocoumarin ring which is catalyzed by $\mathrm{H}_{2} \mathrm{SO}_{4}$, $\mathrm{PPA}$ and $\mathrm{HClO}_{4}$ in the Pechmann reaction through electrophilic substitution.

The benzochromone ring is formed without working at high temperatures and it is concluded that the intermediate as an onium ion, forming in this condition through $\mathrm{S}_{\mathrm{N}} 1$ reaction mechanism.

In a further investigation we are planning to calculate the stability of intermediates of the benzocoumarin and benzochromone with aid of computational chemistry.

\section{Experimental}

M.ps. were taken on a Gallenkamp apparatus and are uncorrected. IR spectra were recorded on a Mattson 1000 FTIR spectrometer, mass spectra on a Zab Spec $(70 \mathrm{eV})$ mass spectrometer, ${ }^{1} \mathrm{H}$ and ${ }^{13} \mathrm{C}$ NMR spectra on a BrukerSpectrospin DPX Avance 400 Ultra Shield and Varian Mercury plus 300 plus spectrometer using TMS as internal standard and electronic spectra (EtOH/DMF) on a UV-1601 spectrophotometer. Commercial reagents and solvents were used.

8-Hydroxy-4-methyl-2H-naphtho[2,3-b]pyran-2-one (2), 9-hydroxy-1-methyl-3H-naphtho[2,1-b]pyran-3-one (3) and 9-hydroxy-2-methyl-4H-naphtho[2,1-b]pyran-4one (4): A suspension of 2,7-dihydroxynaphthalene (1.6 g) in ethyl acetoacetate $(3.9 \mathrm{~mL})$ was slowly added to $80 \%$ $\mathrm{H}_{2} \mathrm{SO}_{4}(10 \mathrm{~mL})$ at $0^{\circ}$ while stirred magnetically. The mixture was kept for $24 \mathrm{~h}$ at r.t. Then ice/water $(100 \mathrm{~mL})$ was added and the resulting solid was washed with water and dried in open air. The solid product was taken in ethanol and the insoluble material was filtered. The insoluble material was crystallized from dimethylformamide to give $4(0.5 \%$ m.p. $318^{\circ} \mathrm{d}$ ) as a colourless powder. The solution was evaporated to dryness on a steam-bath and the remaining solid was dissolved in $10 \%$ aqueous $\mathrm{NaOH}$. The insoluble material was filtered, acidified and crystallized from ethanol to give $2\left(37.6 \%\right.$, m.p. $\left.274^{\circ}\right)$ as a yellowish powder. The filtrate was acidified with conc. $\mathrm{HCl}$ to $\mathrm{pH} 1-2$. The resulting solid obtained after standing overnight was washed with water, dried and crystallized from ethanol to give $3(29.4 \%$, m.p. $284^{\circ}$ ) as a yellowish powder.

Compound 2: ${ }^{1} \mathrm{H}$ NMR (DMSO- $\left.d_{6}, 400 \mathrm{MHz}\right) \delta 2.49$ $\left(3 \mathrm{H}, \mathrm{s}, 4-\mathrm{CH}_{3}\right.$ overlapped by DMSO- $\left.d_{6}\right), 6.32(1 \mathrm{H}, \mathrm{s}, 3-$ $\mathrm{H}), 7.10(1 \mathrm{H}, \mathrm{dd}, J 9,2 \mathrm{~Hz}, 7-\mathrm{H}), 7.15(1 \mathrm{H}, \mathrm{d}, J 2 \mathrm{~Hz}, 9-$ H), $7.59(1 \mathrm{H}, \mathrm{s}, 10-\mathrm{H}), 7.93(1 \mathrm{H}, \mathrm{d}, J 9 \mathrm{~Hz}, 6-\mathrm{H}), 8.24$ $(1 \mathrm{H}, \mathrm{s}, 5-\mathrm{H}), 10.21(1 \mathrm{H}, \mathrm{s}, \mathrm{OH}) ;{ }^{13} \mathrm{C}$ NMR (DMSO- $d_{6}$, $400 \mathrm{MHz}) \delta 17.99,107.53,109.85,113.30,116.74,118.96$, $124.45,125.64,130.63,136.29,150.18,153.021,157.48$, 159.89; MS (EI, 70 e V) m/z $226\left(\mathrm{M}^{+}\right), 209,198,181$, $169,152,141,126,115 ; v_{\max }(\mathrm{KBr}) 3360,1705,1680$, $1622,1564,1478,1446,1398,1331,1238,1139,1062$, $924,892,832,819,739,566,537,512,464 \mathrm{~cm}^{-1} ; \lambda_{\max }$ (EtOH) 356, 289, $235 \mathrm{~nm}$. Compound $3:{ }^{1} \mathrm{H}$ NMR (DMSO- $\left.d_{6}, 400 \mathrm{MHz}\right) \delta 2.84\left(3 \mathrm{H}, \mathrm{s}, 1-\mathrm{CH}_{3}\right), 6.40(1 \mathrm{H}, \mathrm{s}$, 2-H), $7.13(1 \mathrm{H}, \mathrm{dd}, J 9,2 \mathrm{~Hz}, 8-\mathrm{H}), 7.26(1 \mathrm{H}, \mathrm{d}, J 9 \mathrm{~Hz}, 5-$ H), $7.89(1 \mathrm{H}, \mathrm{d}, J 9 \mathrm{~Hz}, 7-\mathrm{H}), 7.99(1 \mathrm{H}, \mathrm{d}, J 2 \mathrm{~Hz}, 10-\mathrm{H})$, $8.02(1 \mathrm{H}, \mathrm{d}, J 9 \mathrm{~Hz}, 6-\mathrm{H}), 10.12(1 \mathrm{H}, \mathrm{s}, \mathrm{OH}) ;{ }^{13} \mathrm{C} \mathrm{NMR}$ 
(DMSO- $\left.d_{6}, 400 \mathrm{MHz}\right) \delta 25.54,108.23,112.57,113.69$, $114.76,116.86,125.13,131.14,131.48,133.62,154.66$, 154.82, 157.30, 159.25; MS (EI, $70 \mathrm{eV}) \mathrm{m} / \mathrm{z} 226\left(\mathrm{M}^{+}\right)$, $211,209,198,181,169,155,152,141,127,115,113$; $v_{\max }(\mathrm{KBr}) 3312,1686,1622,1555,1536,1440,1408$, $1376,1356,1228,1139,1062,953,832,729,662,582$, $537,512,483,441 \mathrm{~cm}^{-1} ; \lambda_{\max }(\mathrm{EtOH}) 352,237 \mathrm{~nm}$. Compound $4:{ }^{1} \mathrm{H}$ NMR (DMSO- $\left.d_{6}, 400 \mathrm{MHz}\right) \delta 2.40(3 \mathrm{H}, \mathrm{s}$, 2- $\left.\mathrm{CH}_{3}\right), 6.33(1 \mathrm{H}, \mathrm{s}, 3-\mathrm{H}), 7.15(1 \mathrm{H}, \mathrm{dd}, J 8.75,2.5 \mathrm{~Hz}, 8-$ H), $7.39(1 \mathrm{H}, \mathrm{d}, J 9 \mathrm{~Hz}, 5-\mathrm{H}), 7.89(1 \mathrm{H}, \mathrm{d}, J 9 \mathrm{~Hz}, 7-\mathrm{H})$, $8.13(1 \mathrm{H}, \mathrm{d}, J 9 \mathrm{~Hz}, 6-\mathrm{H}), 9.32(1 \mathrm{H}, \mathrm{d}, J 2.5 \mathrm{~Hz}, 10-\mathrm{H})$, $10.12(1 \mathrm{H}, \mathrm{s}, \mathrm{OH}) ;{ }^{13} \mathrm{C}$ NMR (DMSO- $\left.d_{6}, 400 \mathrm{MHz}\right) \delta$ $19.18,108.95,112.50,113.79,114.64,117.68,124.43$, $130.03,132.03,135.13,157.75,158.36,163.63,178.94$; MS (EI, $70 \mathrm{eV}) \mathrm{m} / \mathrm{z} 226\left(\mathrm{M}^{+}\right), 209,198,186,181,169$, $158,139,130,113 ; v_{\max }(\mathrm{KBr}) 3440,3120,2928,2720$, $1641,1612,1571,1536,1472,1449,1372,1350,1318$, $1260,1222,1200,1145,1062,969,899,880,838,704$, $620,582,550,505,457 \mathrm{~cm}^{-1} ; \lambda_{\max }$ (DMF) $340,323,270$ nm.

9-Hydroxy-2-methyl-4H-naphtho[2,1-b]pyran-4-one (4) and 9-hydroxy-1-methyl-3H-naphtho[2,1-b]pyran-3one (3) : To a magnetically stirred solution of $\mathrm{H}_{3} \mathrm{PO}_{4}$ (3.6 $\mathrm{mL}, 85 \%), \mathrm{P}_{2} \mathrm{O}_{5}(10.8 \mathrm{~g})$ was rapidly added. Then, a mixture of 2,7-dihydroxynaphthalene $(3.2 \mathrm{~g})$ and ethyl acetoacetate $(7.8 \mathrm{~g})$ was added dropwise to the obtained PPA at viscous state with stirring. The viscous greenish yellow reaction mixture was then heated to $70-80^{\circ}$ for $30 \mathrm{~min}$. with stirring. The brown viscous mass was then cooled and water $(10 \mathrm{~mL})$ was added to it. The solution was kept overnight and the resulting solid was washed with water and dried in open air to give a crude product which was taken into ethanol. The insoluble material was filtered and crystallized from dimethylformamide to give 4 (13.3\%, m.p. $318^{\circ} \mathrm{d}$ ) as a colourless powder. The mother liquor was then concentrated and the crude product was crystallized from ethanol to give $3\left(17.3 \%\right.$, m.p. $\left.284^{\circ}\right)$ as a yellowish powder.

8-Hydroxy-4-methyl-2H-naphtho[2,3-b]pyran-2-one (2) and 9-hydroxy-1-methyl-3H-naphtho[2,1-b]pyran-3one (3): A suspension of 2,7-dihydroxynaphthalene (1.6 $\mathrm{g}$ ) in ethyl acetoacetate $(3.9 \mathrm{~mL})$ was slowly added to $\mathrm{HClO}_{4}$ $(10 \mathrm{~mL})$ at $0^{\circ}$ while stirred magnetically. The mixture was kept for $24 \mathrm{~h}$ at r.t. Then ice/water $(100 \mathrm{~mL})$ was added and the resultant solid was filtered, washed with water and dried in open air. The solid product was dissolved in $10 \%$ aqueous $\mathrm{NaOH}$. The insoluble material was filtered, acidified and crystallized from ethanol to give 2 ( $21.6 \%$, m.p. $\left.274^{\circ}\right)$ as a yellowish powder. The filtrate was acidified with conc. $\mathrm{HCl}$ to $\mathrm{pH} 1-2$. The resulting solid obtained after standing overnight was washed with water, dried and crystallized from ethanol to give $3\left(32.7 \%\right.$, m.p. $\left.284^{\circ}\right)$, as a yellowish powder.

$2,2^{\prime}, 7,7^{\prime}$-Tetrahydroxy [1,1'-binaphthyl] (5) : 2,7Dihydroxynaphthalene $(0.8 \mathrm{~g})$ was placed in a $100-\mathrm{mL} 3-$ necked round-bottomed flask fitted with a mechanical stirrer, dropping funnel and a reflux condenser and dioxan (5 $\mathrm{mL}$ ) was added. The mixture was heated by stirring to 100 $110^{\circ}$ and a solution of $\mathrm{FeCl}_{3} \cdot 6 \mathrm{H}_{2} \mathrm{O}(1.39 \mathrm{~g})$ in dioxan $(2$ $\mathrm{mL}$ ) was added into the flask through the separatory funnel over a period of $5 \mathrm{~min}$. The mixture was refluxed in an iol bath for $10 \mathrm{~min}$., cooled and then poured into water (100$\mathrm{mL})$. Decolourising carbon $(1.2 \mathrm{~g})$ was added, heated, filtered and the filtrate was concentrated on an electric hot plate. The mixture was allowed to cool, and the solid product was filtered. The product was crystallized from water $\left(60 \%\right.$, m.p. $\left.124-125^{\circ}\right)$.

${ }^{1} \mathrm{H}$ NMR (DMSO- $\left.d_{6}, 400 \mathrm{MHz}\right) \delta 6.28(2 \mathrm{H}, \mathrm{d}, J 2.4$ $\mathrm{Hz}), 6.78(2 \mathrm{H}, \mathrm{dd}, J 2.4,8.7 \mathrm{~Hz}), 7.06(2 \mathrm{H}, \mathrm{d}, J 8.8 \mathrm{~Hz})$, $7.66(2 \mathrm{H}, \mathrm{d}, J 8.8 \mathrm{~Hz}), 7.68(2 \mathrm{H}, \mathrm{d}, J 8.7 \mathrm{~Hz}), 8.92(1 \mathrm{H}, \mathrm{s}$, $\mathrm{OH}), 9.17(\mathrm{lH}, \mathrm{s}, \mathrm{OH}) ;{ }^{13} \mathrm{C}$ NMR (DMSO- $d_{6}, 400 \mathrm{MHz}$ ) $106.34,114.45,114.93,115.42,123.16,128.35,129.50$, 136.07, 153.36, 155.53; MS (EI, $70 \mathrm{eV}) \mathrm{m} / \mathrm{z} 318$ $\mathrm{C}_{20} \mathrm{H}_{14} \mathrm{O}_{34}^{+}, 300 \mathrm{C}_{20} \mathrm{H}_{12} \mathrm{O}_{3}^{+}\left(-\mathrm{H}_{2} \mathrm{O}\right), 260 \mathrm{C}_{17} \mathrm{H}_{8} \mathrm{O}_{3}^{+}$ $\left(-\mathrm{CH}_{3} \mathrm{CCH}\right), 242 \mathrm{C}_{17} \mathrm{H}_{6} \mathrm{O}_{2}^{+}\left(-\mathrm{H}_{2} \mathrm{O}\right) ; v_{\max }(\mathrm{KBr}) 3456$, $3232,1622,1526,1472,1449,1350,1257,1206,1110$, $870,828 \mathrm{~cm}^{-1}$.

8, 8'-Dihydroxy-4,4'-dimethyl[9,9'-bi-2H-naphtho[2,3bJpyran]-2,2'-dione (6): Conc. $\mathrm{HClO}_{4}(5 \mathrm{~mL})$ was placed in a 100 -mL 2-necked round-bottom flask fitted with a mechanical stirrer and chilled to $-10^{\circ}$. A mixture of $2,2^{\prime}, 7,7^{\prime}-$ tetrahydroxy $\left[1,1^{\prime}\right.$-binaphthyl $](0.3 \mathrm{~g})$ and ethyl acetoacetate $(1.5 \mathrm{~g})$ was added to the flask with a pasteur pipet over a period of $5 \mathrm{~min}$ by continuous stirring. The mixture was kept for $24 \mathrm{~h}$ at r.t. and ice/water $(100 \mathrm{~mL})$ was added and filtered, washed with water and dried in open air. The dried crude material was chromatographed on a silica gel column (chloroform : ethyl acetate, $1: 1)$ to give the product $(17 \%$, $\left.350^{\circ} \mathrm{d}\right)$.

${ }^{1} \mathrm{H}$ NMR (DMSO- $\left.d_{6}+\mathrm{CDCl}_{3}, 400 \mathrm{MHz}\right) \delta 2.49(3 \mathrm{H}$, s), $2.55(3 \mathrm{H}, \mathrm{s}), 6.11(1 \mathrm{H}, \mathrm{s}), 6.14(1 \mathrm{H}, \mathrm{s}), 6.37(1 \mathrm{H}, \mathrm{s})$, $6.51(\mathrm{~d}, J 2.21 \mathrm{~Hz}), 6.71,6.84,7.06,7.08,7.34,7.37,7.85$, $7.89,7.92,8.06,8.14,9.30,9.34 ;{ }^{13} \mathrm{C}$ NMR $\left(\mathrm{DMF}-d_{6}+\right.$ $\left.\mathrm{CDCl}_{3}, 300 \mathrm{MHz}\right) 18.6,18.8,104.9,109.0,114.2,117.6$, $117.8,119.2,119.6,125.5,126.1,126.1,126.3,130.9$, $131.1,131.5,136.4,136.8,137.1,151.3,153.0,153.3$, $156.1,156.4,158.7,158.9,160.4,160.6$; MS (EI, $70 \mathrm{eV}$ ) $m / z 450, \mathrm{C}_{28} \mathrm{H}_{18} \mathrm{O}_{6} \mathrm{M}^{+}, 404,307,254,226, \mathrm{C}_{14} \mathrm{H}_{10} \mathrm{O}_{3}^{+}$, $198 \mathrm{C}_{13} \mathrm{H}_{10} \mathrm{O}_{2}^{+}(-\mathrm{CO}), 169 \mathrm{C}_{12} \mathrm{H}_{9} \mathrm{O}^{+}(-\mathrm{CHO}), 152,139$, 
127,$115 ; v_{\max }(\mathrm{KBr}) 3344,2944,1696,1616,1472,1385$, $1347,1238,1200,934,889,848,809 \mathrm{~cm}^{-1}$.

9,9'-[Methan]bis [8-hydroxy-4-methyl-2H-naphtho[2,3-b]pyran-2-one] (7) : A solution of linear benzocoumarin $2(1 \mathrm{~g})$ and diethylamine $(0.4 \mathrm{~mL})$ in ethanol $(35 \mathrm{~mL})$ was mixed with formalin $(0.8 \mathrm{~mL})$. The mixture was refluxed for $6 \mathrm{~h}$. After cooling, it was acidified with a solution of conc. $\mathrm{HCl}(2 \mathrm{~mL})$ in ethanol $(5 \mathrm{~mL})$, filtered and the product was purified by crystallization from dimethylformamide to give a yellow powder $\left(32 \%, 332^{\circ} \mathrm{d}\right)$.

${ }^{1} \mathrm{H}$ NMR (DMSO- $\left.d_{6}, 400 \mathrm{MHz}\right) \delta 2.33(6 \mathrm{H}, \mathrm{s}), 4.61$ (2H, s), $6.25(2 \mathrm{H}, \mathrm{s}), 7.29(2 \mathrm{H}, \mathrm{bd}), 7.80(2 \mathrm{H}, \mathrm{d}, J 8.9 \mathrm{~Hz})$, $8.05(2 \mathrm{H}, \mathrm{s}), 8.15(2 \mathrm{H}, \mathrm{s}), 11.03(2 \mathrm{H}, \mathrm{s},-\mathrm{OH}) ;{ }^{13} \mathrm{C} \mathrm{NMR}$ $\left(\right.$ DMF- $\left.d_{6}, 300 \mathrm{MHz}\right) 17.7,109.1,113.8,117.0,118.7$, $126.1,126.4,129.5,136.3,143.4,147.7,150.8,153.3$, 154.6, 160.6; MS (EI, $70 \mathrm{eV}) \mathrm{m} / \mathrm{z} 465 \mathrm{C}_{29} \mathrm{H}_{20} \mathrm{O}_{6}\left(\mathrm{M}^{+}\right)$, $385,254,239,232,214,205,195,179,157$; $v_{\max }(\mathrm{KBr})$ $3360,1696,1625,1568,1478,1340,1289,1232,1196$, $1084,1017,982,940,896,854,803,649,515,457 \mathrm{~cm}^{-1}$.

\section{Acknowledgement}

This work was supported by the Research Fund of The University of Trakya. The authors are grateful to Dr. Ö. Zaim for his support in this study.

\section{References}

1. A. Borgagna, M. Longobardi, E. Mariani, P. Schenone, S. Russo, S. Vitagliano, V. Denovellis and E. Marmo, Farmaco. Ed. Sci., 1988, 43, 857.

2. R. O'Kennedy and R. D. Thormes, "Coumarins : Biology, Applications and Mode of Action", Wiley, Chichester, 1997; M. Zahradnik, "The Production and Application of Fluorescent
Brightening Aagents", Wiley, New York, 1992; C. Karapire, H. Kolancilar, Ü. Oyman and S. Icli, J. Photochem. Photobiol. : A Chem., 2002, 15, 173.

3. (a) $\mathrm{H}$. von Pechmann and C. Duisberg, Ber. Dish. Chem. Ges. 1884, 17, 929; (b) J. R. Jonson, Org. Rect., 1942; 1, 210 ; (c) G. Jones, Org. React., 1967, 15, 204; (d) G. Brufola, F. Fringuelli, O. Piermatti and F. Pizzo, Heterocycles, 1996, 43, 1257.

4. H. Appel, J. Chem. Soc., 1935, 1031.

5. H. Simonis and P. Remmert, Chem. Ber. 1914, 47, 2229.

6. I. Goodall and A. Robertson, J. Chem. Soc., 1936, 426.

7. S. M. Sethna, N. M. Shah and R. C. Shah, J. Chem. Soc., 1938, 228.

8. M. K. Potdar, S. S. Mohile and M. M. Salunkhe, Tetrahedion Lett., 2001, 42, 9285.

9. T.-S. Li, Z. H. Zhang, F. Yang and C. G. Fu, J. Chem. Res. (S), 1998, 1, 38.

10. V. Singh, J. Singh, K. P. Kaur and G. L. Kad, J. Chem. Res. (S), 1997, 2, 58.

11. B. B. Dey and A. K. Lakshminarayanan, J. Indian Chem. Soc., 1932, 9, 149; R. Adams and J. W. Mecorney, J. Am. Chem. Soc., 1944, 66, 802.

12. J. H. Pardanani and S. Sethna, J. Indian Chem. Soc., 1978 , 55, 806

13. Z. F. Tao, X. Qian and M. Fan, Tetrahedron, 1997, 39 , 13329.

14. Ü. Oyman and K. Günaydın Bull. Soc. Chim. Belg., 1994, 103.

15. Ng. Ph. Buu-Hoi and D. Lavit, J. Chem. Soc., 1956, 1743.

16. O. S. Wolfbeis, Monatsh. Chem., 1978, 109, 1413.

17. R. N. Lacey, J. Chem. Soc., 1954, 854.

18. K. Brass and R. Patzelt, Chem. Ber, 1937, 1341.

19. P. D. Re. L. Verlicchi and I. Setnikar, J. Org. Chem., 1960, 25, 1097. 